\title{
The influence of visual and hearing stimuli on the performance of young tennis athletes aged $12-15$ years
}

\author{
Stamboulis $A^{1}$., Mavvidis $A^{1}$., Dimitriou $V^{2}$., Giampanidou $A^{3}$. \\ 1.Democritus University of Thrace,
}

Department of Physical Education \& Sport Science, Komotini

2.Aristotles University of Thessaloniki ,

Department of Mathematics, Thessaloniki

3.Aristotles University of Thessaloniki ,

Department of Economics, Thessaloniki

\begin{abstract}
The purpose of the study was to examine the effects of visual and hearing influences on the performance of young tennis players aged between $12-15$ years old. The sample comprised 60 athletes, 30 males and 30 females respectively with the average age of $13,61( \pm 1,48)$ years and previous competitive experience in local and/or peripheral levels. The method used during the study was completed in two sessions. Firstly, all participants were measured according to two variables (precision, score) while performing a forehand and a backhand drive test where competence was being registered. The measurings during the performance of these two strikes were imitially realized with the insertion of visual and later of hearing stimuli. A week later, the measurings were repeated using the same sample (reliability control). The results proved that the values of the second measuring were clearly better than the values of the first one. However, the measuring's reliability ranges within satisfactory levels $(r=.83)$. Moreover, the negative effects of visual and hearing influences upon the athlete's performance proved to be mainly visual and secondly hearing. In conclusion, the present study showed that the visual and hearing influences have negative effects on the performance of young tennis players between $12-15$ years of age, who should be trained accordingly, so as to overcome successfully those influences and perform their best!
\end{abstract}

Key words: tennis test; age categories, forehand (fh); backhand (bh); boys; girls. visual and hearing influences on the performance

\section{INTRODUCTION}

The human body constantly receives both external and internal stimuli. Any human activity develops simple and complex reactions through responses to external stimuli. (12)

The human organism perceives different stimuli through the sensory receptors which receive, convert and transmit the energy of inner and outer signals to the nervous system. Senses are exposed to numerous stimuli which define human reactions towards any unusual or different in the environment. (23)

There are three sensory systems ( visual, hearing and kinesthetic ) which provide a complex amount of information for the different environmental elements and determine human position in it. (21)

This kind of information is called exogenous information coming from the outside of the body where they appear. The main source of exogenous information is certainly vision. The second most important exogenous information derives from hearing. (18)

It is very important for those taking part in sports to develop the ability to focus to a small number of events, but it is even more important to learn to select certain points which will enhance learning and performing abilities. (4) It is essential that they identify the dexterities and the points of the game to which they have to draw their attention and, at the same time, be able to elicit responses and ignore unimportant events or stimuli (10)

It is, thus, evident, the correlation and the impact of the stimuli on the athletic performance and specifically on athletic records. (3) The definition of the athletic performance is closely related to the outcome produced through athletic actions. (4)

In conclusion, when visual and hearing stimuli affect a certain activity, this is performed through the central nervous system and the system processing information and thus they affect mentally controlled movements. As for the athletic records, the question is to what extent do visual and hearing stimuli affect the automated mechanical efficiency.

The bibliography concerning the factors affecting records in sports lacks scientific documentation. On the other hand, and this is obvious through the research of $(1,15)$ performance stability is of high importance. Especially in tennis a potential failure of a target or a decrease in performance is often due to hearing and visual stimuli which are considered by the athlete as factors that decrease performance. Nevertheless, the most effective reaction which these stimuli evoke remains unexplored.

Detailed knowledge of the degree and the direction of the effect of these sensory stimuli and the specific ways of coping could significantly contribute in analysing operating mechanism during training and tennis games. It is, thus, very 
important to reveal the correlation between the effect of hearing and visual stimuli and performance in tennis, since visual perceiptive ability is a main factor in a player's coordination. (7)

\section{METHODS}

The scientific research methods used comply with the standards of American College of Sports Medicine`s policies with regards to animal and human experimentation.

\section{Participants}

We used the random sampling technique and 60 tennis athletes participated in the survey, 30 boys and 30 girls, $12-15$ years of age (average 13,61 $\pm 1,48$ years) having training experience of $3.78( \pm 1.80)$ years. All participants had already participated in local or regional tennis games (average years $1.78 \pm 1.54$ ). The training schedule during the experiment included training 3 times a week.

Performance. The performance was evaluated according to the test Forehand Drive and Backhand Drive described by (25) with the following qualitative characteristics: reliability $>0,88$ and validity, $r=0,71$.

The procedure was completed in two stages: first measurement, the three scheduled training sessions had already been completed within a week, and they weren`t related in any way to the measurement, and then followed the second measurement.

First measurement. In the first measurement, athletes were not given a test to familiarize with the skill. They followed the usual warm up before any training unit. The first measurement comprised 10 consecutive forehand strokes and 10 consecutive backhand strokes (figure 2 ). A similar procedure followed two more times, the first involving visual disturbance, where one athlete performed the test, two other athletes where standing on the left and on the right end of the service line and where exchanging balls in a rhythmic way while at the same time two more were walking in the opposite direction on the base line. (figure 3). During the hearing disturbance, while the athlete tested was performing the test, was heard a loud noise of applause of constant intensity and duration from two CD players placed on the net posts (figure 4 ). The athletes hit the ball from the base line opposite the numbered and separated areas of the court. The feeding was performed to all participants by the same experienced coach at a certain point on the opposite court. The athletes were trying to aim at the marked areas on the opponent's court in order to collect as many scores as they could and perform as many successful strokes to the target. Every stroke was graded from 1 to 9 points, depending on the area where the ball landed. If the ball went higher over the rope before it landed, then the stroke received 0 points and was considered unsuccessful. The total score was assessed from the total points plus the percentage of the successful points gathered by the athlete during the three different measurements and is recorded on an especially formed record performance sheet ( figure 5)

In between stage. The training schedule is followed regulary in between the measurements, without making any connections with the test and without any similar training activities. In this way the test measures each time the performance ability of the athletes tested on the two strokes examined. There was not applied an intervention program in between the measurements since in the present survey is exclusively studied the influence of visual and hearing stimuli to young tennis athletes, and specifically to their performance of forehand and backhand strokes and not after applying an intervention program.

Second measurement. It was performed in order to check the credibility of the measurements during the first one. The initial measurements were repeated. The person who conducted the test reminded the athletes that their performance would be recorded on camera, the results would be compared and announced and the best athletes would be awarded a prize. After the end of the procedure, the participants were informed on the purpose of the measurements and of the general testing procedure.

In order to check the influence of the age and sex on the successful strokes, the Two- Way ANOVA test was used. As for checking the difference of performance with and without visual and hearing disturbance, the one-way ANOVA test was used again.

\section{RESULTS}

As shown in figure 4, score gathering with visual disturbance is significantly lower, the differences in performance records are statistically important compared to those without disturbance, and in both cases of disturbance they are statistically significant $(p<.001$, table 1$)$ 


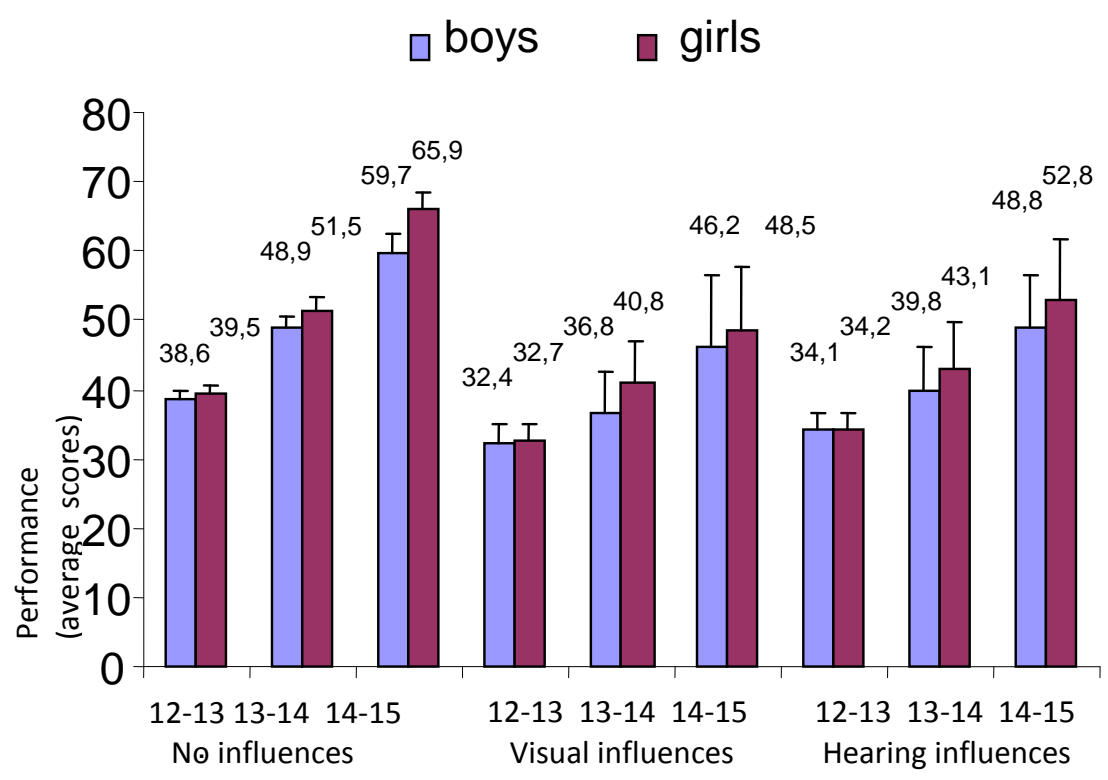

Figure 1 : Total scores through all three parameter test ( without disturbance, with visual and hearing disturbance ) for athletes of all three age groups and of both sexes

Table 1. Difference in performance : with visual and hearing disturbance and without disturbance. (One way ANOVA)

\begin{tabular}{r|r|r|r|r|r|r}
\hline & & $\begin{array}{c}\text { Sum of } \\
\text { Squares }\end{array}$ & Df & $\begin{array}{c}\text { Mean } \\
\text { Square }\end{array}$ & F & Sig. \\
\hline \multicolumn{1}{c|}{ visual } & Between & 4600,367 & 27 & 170,384 & 25,434 &, 000 \\
\hline & Within Groups & 214,367 & 32 & 6,699 & & \\
\hline & Total & 4814,733 & 59 & & & \\
\hline hearing & Between & 4810,817 & 27 & 178,178 & 30,309 &, 000 \\
\hline & Within Groups & 188,117 & 32 & 5,879 & & \\
\hline & Total & 4998,933 & 59 & & & \\
\hline
\end{tabular}

Also, the results of significance level $5 \%$ are (figure 1 ) :

1. Children's age significantly influences the collecting of marks during measurements when there exists no disturbance, visual and hearing, and the fact is that the older the children are the more marks they get.

2. There is no significant influence of the sex on marks collecting during measurements with visual and hearing disturbance.

\section{DISCUSSION}

The present study aims to examine the influence of visual and hearing stimuli on young tennis athletes performance. Roughly, the results justified the initial assessments, according to which the visual and hearing stimuli affect the automatic mechanical performance and more specifically athletic records in sports.

During the first measurement, athletic performance was better during the test without the disturbances, while, later, hearing and most important visual stimuli affected performance negatively. Similar conclusions were drawn during the second measurement (test-retest method), which confirms both the credibility of measurement and the negative influence of visual disturbance. In tennis, the influence of visual stimuli was also justified, since it is well known by the existing bibliography, that visual processing of visual signals lasts more than that of hearing ones (23), and that the conditions of implementation and of measurement remain stable and ideal, which establishes a non-stressful background as perceived by athletes.

External stimuli and the reactions they cause are a major factor of development of activity as for the athletes stimulation and the athletes' perceptive response to stimuli. More specifically, the hearing and visual stimuli, assessed 
through the present survey, affect negatively the performance of young tennis athletes. The same applies to the athletes of different levels of performance (average athletes- professional athletes) as well as to those who don't train at all (23), As a result, there is an overall consent that hearing and visual disturbances influence performance negatively and it is necessary to be found ways for resolving the problems that those factors cause to all aspects in sports.

Recurring to bibliography, (13), the sensitive phases initially concern athletes from 10-12 years of age and later athletes at the age of 15. Another researcher asserts that 14-16 years of age is the ideal age to exploit psychological parameters in order to evaluate the player's performance. (19) According to another point of view (5), the effect of the psychological profile during this first sensitive period and during the stage of high performance of the athlete is of little importance reaching 50\%. Indicatively are mentioned studies on the impact of stress at different times (6), on the influence of stress as a different factor during performance (12), on the negative thoughts and subjective perception of the stressful enviroment (12), cognitive advantage (22), connection between attention and athletic performance $(8,14)$, as well as stress and ability to concentrate (8). In the present research, the athletes were asked whether or not they felt that the experimental conditions were really coercive and they considered them to be slightly coercive, which suggests the reliability of the measurements results, since the measurements were not taken under psychologically stressful conditions.

The qualitative differences in the behaviour of young athletes are influenced by the ability during game performance. Generally, the very good players at this age are less influenced by psychological burdens caused by the stimuli examined in the present study. They are more concentrated on the game, and are not much affected by the problems outside the court. Hearing and visual disturbances results are here presented compared with another study on adult tennis players. (11) As it is clear in the present study, the visual disturbances mostly affect in a negative way more players at the age of 12-13. When an unsuccessful attempt happens, the visual disturbances are to blame at an overall $70 \%$ negative while the respective hearing at an overall $40 \%$. (11) When trying, though, to interpret and draw useful suggestions for the training techniques, one should express a basic hesitation, which is that when there is the case of influencing factors at these ages, it is extremely difficult to draw conclusions and general training interventions for a large group of athletes 'this should only apply to each and every individual separately. (20).

As for the fact of visual dominance and perception of visual stimuli, during the study, although vision contributes significantly in motion control, its role is not always positive, as in many cases those who undergo different stimuli state that visual control dominates other senses (visual dominance) and that through vision information inevitably attracts attention (visual perception). (17) In cases where there is a confusion of sensory information, as for example preference to visual information, there may appear delayed or false answers. Even if there are conflictine available receptors on the skin, the muscles, the joints and the inner ear, the human being continue to take decisions based on the information received through vision. This is useful, since, in many cases visual information is very important and in other cases trusting vision may evoke negative results during performance. (16)

It is worthmentioning that visual dominance obstracts the additional enhancement received through other kinds of sensory information. Sometimes visual dominance, while other sources could prove to be more appropriate, drives to the decrease in performance. It has been proved that it negatively affects performance during movement where quick motion reactions are required. If vision is used with voluntary information processing approach it would be slow and would require close attention. If, on the other hand, kinaesthetic information is used, the answers will be really fast (17). Studies conducted to fencers (9) suggest that in each and every case visual information has been used, this has slowed down the athletes' reaction and drawn their attention away from more relevant kinesthetic information. The reactions to visual signals are slower than to hearing ones, because the converting of the visual energy into tone of the nervous system, which through the bark of the eye is transmitted to the brain, lasts $30 \mathrm{~ms}$ more than the same process of the hearing stimuli (24). Likewise, when a trainee willingly concentrates on certain visual information, this could drop performance levels. A voluntary information processing approach would move control from the relatively quick peripheral system to the slower focal system. Performance deteriorates by stimuli which intervene in natural processing approach during voluntary activities $(2,26)$, which require attention and controlled approach. It is worthmentioning that athletes of high performance records have developed many specialized unvoluntary processes.

For the defining and approach of visual and kinesthetic information which are at the same time very quick and efficient for the correction of mistakes, one of the most important and basic factors of their training.

\section{PRACTICAL APPLICATIONS}

The results of the current survey support the findings and conclusions of our previous research. Being aware of the way through which the hearing and visual stimuli influence the athletes and their performance, coaches and sports psychologists will be able to design more efficient programmes for athletes' psychological support and athletes themselves will be able to overcome any hearing and visual disturbances in order to improve their performance. In fact, the benefits of this kind of programmes become even more significant when the person in charge can identify the needs of each and every athlete and adapt the technique accordingly, so that the athletes can overcome the disturbances and the coach develop the proper technique based both on individual training requirements and skills to be practiced.

Examining the results of the current survey, we have been able to identify a kind of mechanism through which the hearing and visual stimuli affect negatively the athletes performance. Therefore, the athletes themselves should be encouraged to practice and use improvement techniques of reacting to these hearing and visual stimuli. Moreover, the choice of the right psychological advice and influence against internal and external disturbances is also important. In this way, both training requirements and athlete's needs will be taken into consideration. This means that coaches should be able to identify the important and distinctive features of each athlete's skills as well as his/her weaknesses when 
psychological factors are concerned (e.g. hearing and visual sensitivity, excessive stress, lack of attention and concentration etc.) and accordingly adapt training protocols to improve individual performance.

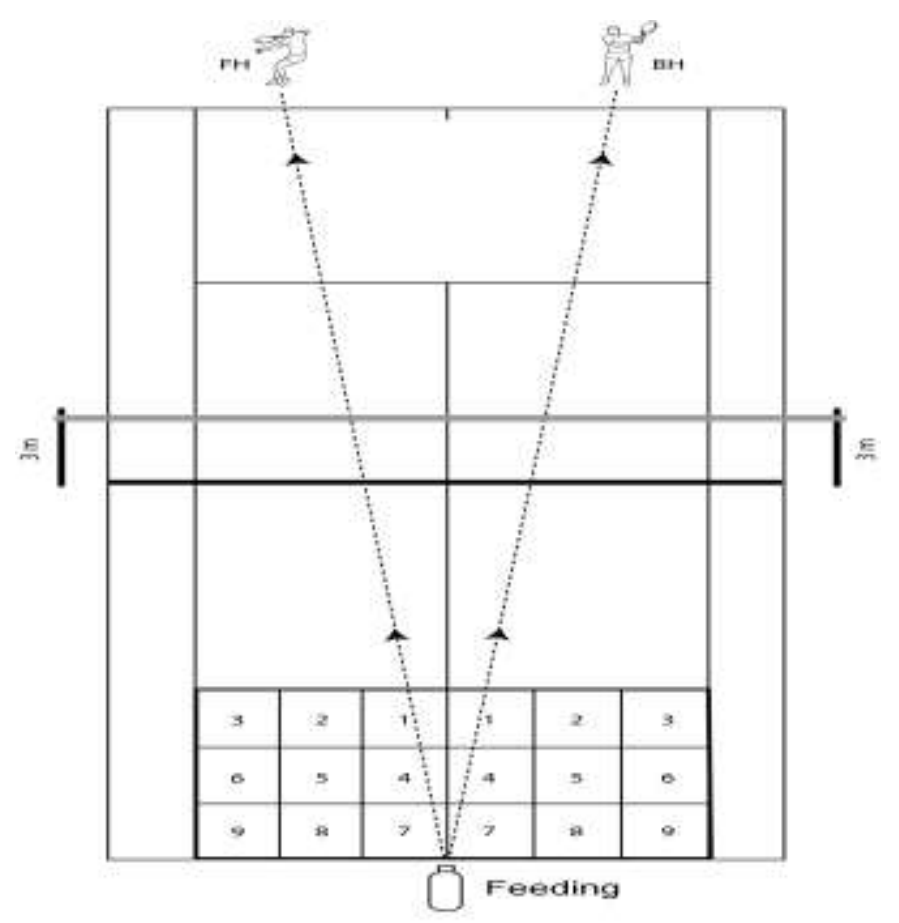

Figure 2: Modification of the court based on test measurements.

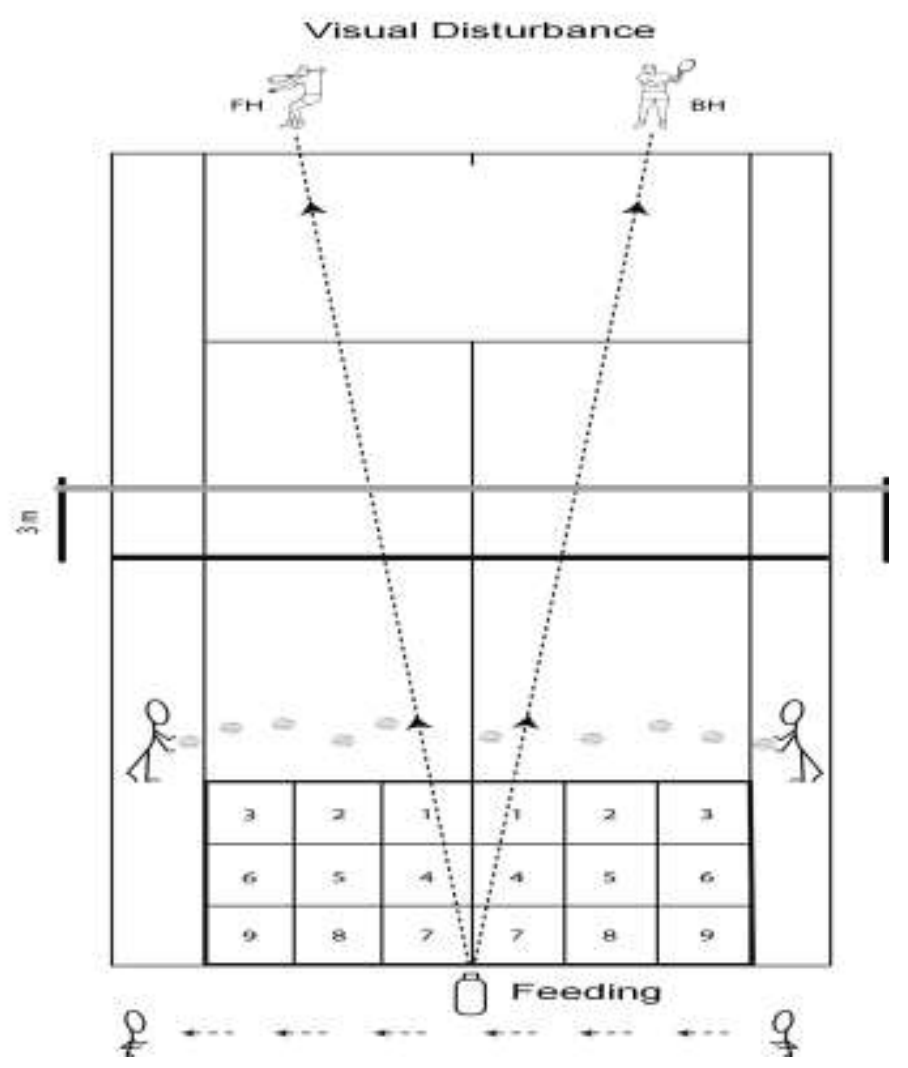

Figure 3: Modification of the court based on test measurements with visual disturbance. 


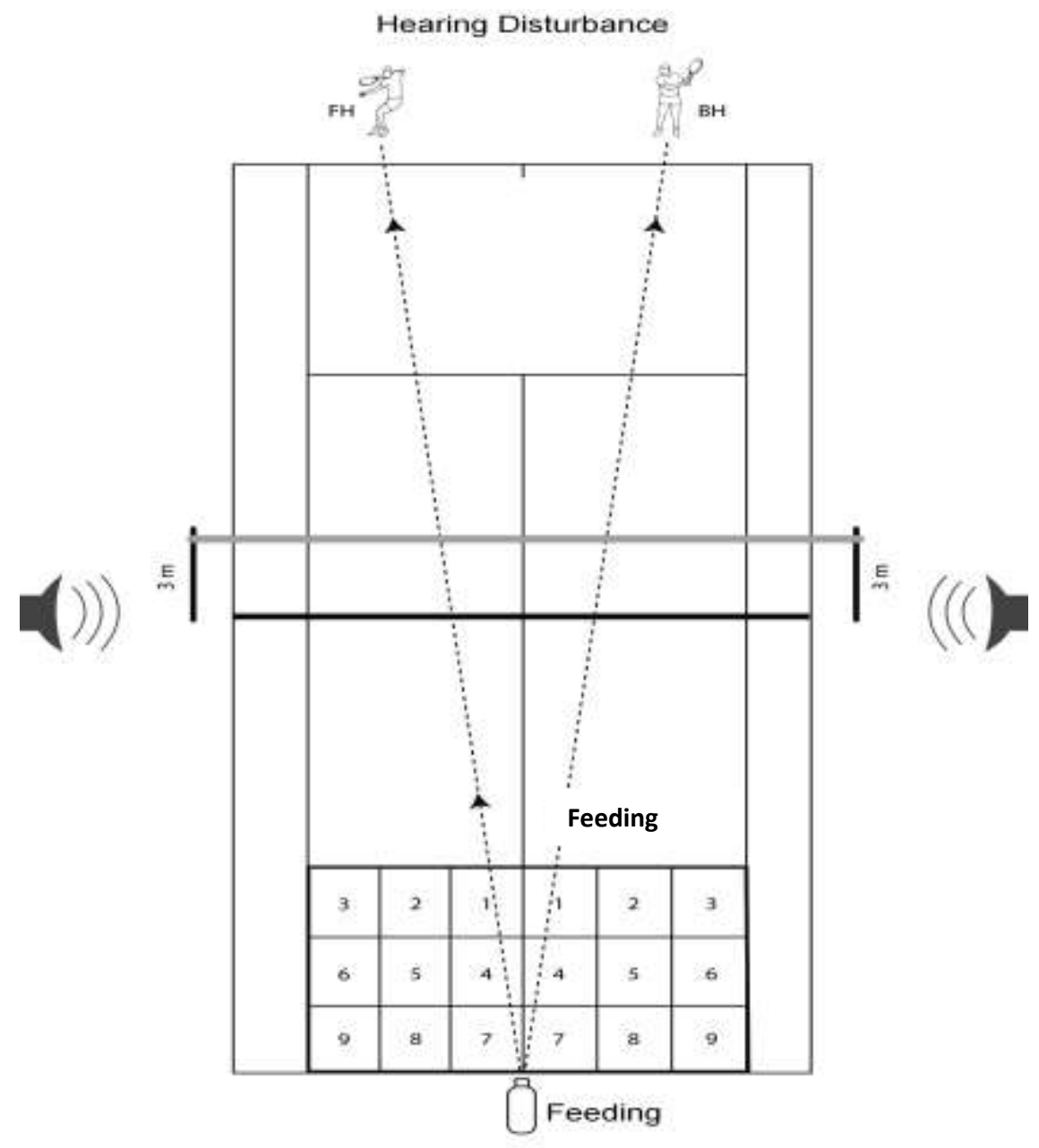

Figure 4: Modification of the court based on test measurements with hearing disturbance.

\begin{tabular}{|c|c|c|c|}
\hline Name: & & $\begin{array}{l}\text { Score } 1^{\text {st }} \\
\text { Forehand-Backhand }\end{array}$ & $\begin{array}{l}\text { Score } 2^{\text {nd }} \\
\text { Forehand-Backhand }\end{array}$ \\
\hline $\mathrm{A} / \mathrm{N}$ & & $\begin{array}{lll}\mathrm{ND}^{1} & \mathrm{VD}^{2} & \mathrm{HD}^{3}\end{array}$ & $\mathrm{ND}^{1} \mathrm{VD}^{2} \quad \mathrm{HD}^{3}$ \\
\hline & 1 & & \\
\hline & 2 & & \\
\hline & 3 & & \\
\hline & 4 & & \\
\hline & 5 & & \\
\hline & 6 & & \\
\hline & 7 & & \\
\hline & 8 & & \\
\hline & 9 & & \\
\hline & 10 & & \\
\hline Total & & & \\
\hline
\end{tabular}

ND'-No disturbanance, VD²-Visual disturbance, $H D^{3}$-Hearing disturbance

Figure 5: Record performance sheet 


\section{REFERENCES}

1. Ausing, I., Psychische Anforderungsbewältigung im Tenniswettkampf.Entwicklung eines theoretischen Anforderungsprofils als Grundlage für die psychologische Arbeit im Training, Deutsche Sporthochschule Koeln: Diplomarbeit, 1996.

2. Keele W.S., Movement control in skilled motor performance., Psychological Bulletin, 1968, 70: 387 - 403.

3. Carl, K., Training und Trainingslehre in Deutschland, Schorndorf: Hofmann, 1983.

4. Cristina, R. \& Corcos, D., Coaches Guide to Teaching Sport Skills, . Champaign, IL: Human Kinetics, 1994.

5. Gabler, H., Talentsuche und Talentforderung im Tennis. In: Gabler H. und Zein B.(Red.), Talentsuche und Talentforderung im Tennis., Ahrensburg: Czwalina, 1984, 9-33.

6. Gould,D., Jackson, S., \& Finch, I., Sources of stress in national champion figure skaters, Journal of Sports Exercise Psychology, 1993, 15(2): $134-159$.

7. Grosser, M. \& Schoenborn, P., Training im Kinder- und Jungendtennis, Meyer \& Meyer Verlag, 2008.

8. Janelle, C., Singer, R., Williams, M., External distraction and attentional narrowing: visual search evidence, Journal of Sport Exercise Psychology, 1999, 21: 70-91.

9. Jordan, T.C., Charateristics of visual and proprioceptive response times in the learning of a motor skill, $\underline{\text { Journal of }}$ Experimental Psychology, 1972, 24 (4): 536-543.

10. Lavie, N., Perceptual load as a necessary condition for selective attention, Journal of Experimental Psychology: Human Perception and Performance, 1995, $\quad$ 21(3): 451-468.

11. Majer, P., Leistungsfaehigkeit und Leistungsstabilitaet im Tennis, Ahrensburg bei Hamburg: Czwalina, 1988.

12. Martens, R., Coaches guide to sport physiology, Champaign IL: Human kinetics, 1994.

13. Martin, D., Zielsetzung und Leistungsentwicklung im Kindertraining, In: Howald H. und Hahn E.(Red.), Kinder im Leistungssport, Basel: Huber, 1982, 208-217.

14. Moran, A.P., The psychology of concentration in sport performers: A cognitive analysis. Champaign IL: Taylor \& Francis, 1996.

15. Mueller, E. \& Krieger, J., Die psychische Belastung des Tennisspielers im Wettkampf und Moeglichkeiten ihrer Beeinflussung, Leistungssport, 1984, 33-37.

16. Rose, J.D., Christina, W. R. A., Multilevel approach to the study of motor control and learning (2end ed.), San Francisco: Pearson Benjamin Cummings, 2006.

17. Schmidt R., Motor learning and performance, Champaign, IL: Human Kinetics, 1993.

18. Schmidt, A. R. Wrisberg, A. C. (eds), Motor learning and performance, Champaign, IL: Human Kinetics, 2008.

19. Schoenborn, R., Leistungslimitierende und Leistungsbestimmende Faktoren, In: Gabler, H. und Zein B.(Red.), Talentsuche und Talentforderung im Tennis. Ahrensburg: Czwalina, 1984,51-75.

20. Sewel,I D. \& Nesti, M., Individual differences in competitive state anxiety, $\underline{\text { Journal of }}$ Sport Sciences,1998, 19: 385-395.

21. Sharkey, B., Gaskill, S., Sport Physiology for Coaches, Champaign IL: Human Kinetics, 2006.

22. Starkes, J. L. \& Allard F. (Eds.), Cognitive issues in motor control, Champaign IL: North Holland, 1993.

23. Weinberg, R.S.\& Gould, D., Foundations of sport and exercise psychology, Champaign IL: Human Kinetics ( $5^{\text {th }}$ ed.), 2011.

24. Weineck, J., Optimales Training - Leistungsphysiologische Trainingslehre unter besonderer Beruecksichtigung des Kinder - und Jugendtrainings, Erlangen: Spitta, 2002.

25. Wiebe, R., Koordinationstest im Sportspiel Tennis. Deutsche Sporthochschule Koeln: Diplomarbeit, 1980.

26. Wulf, G. Attentional focus and motor learning, Bewegung und Training (e-Journal), 2007, 1-10.

\section{ACKNOWLEDGEMENTS}

The research in this thesis would have taken far longer to complete without the encouragement from many others. It is a delight to acknowledge those who have supported and encouraged me.

I would like to thank my colleagues at other tennis clubs who provided unhindered access to both human resources and technical support, as well as tennis athletes themselves who willingly participated in the research.

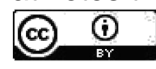

This work is licensed under a Creative Commons Attribution 4.0 International License. 